\title{
K13 propeller domain mutations and pfmdr1 amplification in isolates of Plasmodium falciparum collected from Thai- Myanmar border area in 2006-2010
}

\author{
Papichaya Phompradit ${ }^{1}$, Wanna Chaijaroenkul ${ }^{1}$, Phunuch Muhamad $^{2}$ and Kesara Na-Bangchang $^{1}$ \\ ${ }^{1}$ Center of Excellence in Pharmacology and Molecular Biology of Malaria and Cholangiocarcinoma, Chulabhorn International \\ College of Medicine, Thammasat University, Thailand; \\ ${ }^{2}$ Drug Discovery and Development Center, Office of Advanced Science and Technology Thammasat University, Thailand
}

\begin{abstract}
The K13 propeller domain mutation and pfmdrl amplification have been proposed as useful molecular markers for detection and monitoring of artemisinin resistant Plasmodium falciparum Welch, 1897. Genomic DNA isolates of P. falciparum was extracted from 235 dried blood spot or whole blood samples collected from patients with uncomplicated falciparum malaria residing in areas along the Thai-Myanmar border during 2006-2010. Nested polymerase chain reaction (PCR) and sequencing were performed to detect mutations in K13 propeller domain of P. falciparum at codon 427-709. Pfmdr1 gene copy number was determined by SYBR Green I real-time PCR. High prevalence of pfmdrl multiple copies was observed (42.5\% of isolates). The presence of K13 mutations was low $(40 / 235,17.2 \%)$. Seventeen mutations had previously been reported and six mutations were newly detected. The C580Y was found in two isolates (0.9\%). The F446I, N458Y and P574L mutations were commonly detected. Seven isolates had both K13 mutation and pfmdr1 multiple copies. It needs to be confirmed whether parasites harbouring both K13 mutation and pfmdr1 multiple copies and/or the observed new mutations of K13 propeller domain are associated with clinical artemisinin resistance.
\end{abstract}

Keywords: falciparum malaria, artemisinin resistance, molecular marker, PF3D7_1343700, sequencing

Decline in clinical efficacy of artesunate-mefloquine, the artemisinin-based combination therapy (ACT), has been continuously reported over the two decades of its use as the first-line treatment for acute uncomplicated Plasmodium falciparum malaria in Thailand (Na-Bangchang et al. 2010, 2013). True resistance of the parasite to artemisinins was confirmed in Cambodia and Thailand (Noedl et al. 2008, Dondorp et al. 2009).

This provokes serious worldwide concerns for vigorous and continuous surveillance and monitoring systems to control artemisinin resistance (WHO 2015). Investigations of in vivo and in vitro sensitivity of malaria parasites to antimalarial drugs are the key approaches to support such systems. Recently, validated molecular markers have been integrated as a complimentary tool for identification and prediction of the trend of antimalarial drug resistance (Antony and Parija 2016).

Among all molecular markers, the most important breakthrough is the identification of artemisinin-resistant genetic marker PF3D7_1343700 kelch propeller domain (K13-propeller) by Ariey and colleagues in 2014 (Ariey et al. 2014). Strong correlation has been found between the presence of the dominant mutant K13-propeller alleles, in vitro parasite survival rate, in vivo parasite clearance rate and the spread of artemisinin resistance in western Cambodia (Ariey et al. 2014, Ashley et al. 2014). Accumulating evidence of K13 mutations were subsequently reported in parasite populations in areas of the Greater Mekong Subregion, particularly Cambodia, Thailand, Myanmar and Vietnam (Menard et al. 2016a).

The identified K13 mutations C580Y, Y493H and R539T were shown to be associated with the delay in parasite clearance both in vitro and in vivo (Ariey et al. 2014). However, these mutations were not detected in P. falcipar$u m$ isolates in African countries (Conrad et al. 2014, Cooper et al. 2015, Huang et al. 2015a, Menard et al. 2016b).

The K13-propeller mutation is currently proposed as a useful molecular marker for large-scale surveillance of artemisinin resistance. In contrast, $P f m d r l$ amplification is the key molecular marker of resistance of $P$. falciparum to ACT in South-East Asia. Evidence supports a link between increased pfmdr1 copy number and ACT treatment failure or reduced drug susceptibility in vitro in field parasite isolates (Cui et al. 2015).

The present study provides information on K13 propeller domain mutations and $p f m d r l$ amplification in isolates 
of $P$. falciparum collected from patients with acute uncomplicated falciparum malaria residing in areas along the Thai-Myanmar border following treatment with a threeday artesunate-mefloquine combination.

\section{MATERIALS AND METHODS}

\section{Study site and sample collection}

The study was conducted in areas along the Thai-Myanmar border during 2006-2010. Ethical approval of the study protocol was obtained from the Ethics Committee of the Ministry of Public Health of Thailand. Written informed consents were obtained from all patients before study participation. Inclusion criteria for patient enrollment were according to the World Health Organisation protocol for areas with low-to-moderate malaria transmission (Adeel et al. 2003): axillary temperature $\leq 37.5^{\circ} \mathrm{C}$ or recent history of fever and a slide-confirmed Plasmodium falciparum mono-infection with a parasite density of 1,000-100,000 asexual parasites $/ \mathrm{ml}$. A total of 235 blood samples ( 95 dried blood spots and 140 whole blood samples) were collected from patients with acute uncomplicated falciparum malaria (age $\geq 18$ years, 183 Burmese and 52 Thais) prior to treatment with a 3-day artesunate-mefloquine combination. Of these samples, 227 samples were collected from Mae Sot, Tak province and 8 samples were collected from Ranong province, Thailand. Thirty-three, 60, 51, 85 and 6 samples were collected in 2006, 2007, 2008, 2009 and 2010 , respectively.

\section{DNA extraction and detection of K13 mutations and pfmdr1 amplification}

Genomic DNA of each parasite isolate was extracted from dried blood spots or whole blood samples using a commercial DNA extraction kit (QIAGEN, Hilden, Germany). For the detection of mutations of K13 propeller domain of $P$. falciparum, nested PCR was performed to amplify 849 bp PCR product (at codon 427-709) according to the method described by Ariey et al. (2014) using the following primers: K13_PCR_F (CGGAGTGACCAAATCTGGGA) and K13 PCR_R (GGGAATCTGGTGGTAACAGC) for first PCR and K13_N1_F (GCCAAGCTGCCATTCATTTG) and K13_N1_R (GCCTTGTTGAAAGAAGCAGA) for nested PCR. Each PCR product ( $40 \mu 1$ ) was subsequently sent to the outsourced company for sequencing. Consensus forward and reverse sequences were generated and aligned using DNASTAR (DNASTAR Inc., Madison, Wisconsin, USA) with the K13 sequence of the 3D7 strain (PF3D7_1343700) as the reference.

Pfmdrl gene copy number in all samples was determined by SYBR Green I real-time PCR (iCycler ${ }^{\mathrm{TM}}$, Bio-Rad, California, USA) using the default thermocycler program: $10 \mathrm{~min}$ of pre-incubation at $95^{\circ} \mathrm{C}$, followed by 40 cycles for $15 \mathrm{sec}$ at $95^{\circ} \mathrm{C}$ and $1 \mathrm{~min}$ at $60^{\circ} \mathrm{C}$. The oligonucleotide primers used were those previously designed by Ferreira et al. (2006) with modification. Individual real-time PCR reaction was carried out in a $25 \mu 1$ reaction volume in a 96-well plate containing $2 \mu \mathrm{l}$ of DNA (50 ng), $1 \mu \mathrm{M}$ each of sense and antisense primer and $12.5 \mu$ l of Platinum ${ }^{\mathrm{TM}}$ PCR SuperMix (Invitrogen, California, USA). The $2^{-\Delta \Delta \mathrm{Ct}}$ method of relative quantification was adapted to estimate copy number in genes of $P$. falciparum. The genomic DNA extracted from 3D7 and $\mathrm{Dd} 2$ clones of $P$. falciparum known to harbour a single and four copies of this gene, respectively, were used as a calibrator, while $P f-\beta$-actin 1 served as the house-keeping gene in all experiments.

\section{RESULTS}

\section{Prevalence of K13 propeller domain polymorphisms and $p$ fmdr 1 amplification}

Results of the sequencing analysis of the K13 propeller domain showed that 40 out of 235 (17.2\%) Plasmodium falciparum isolates carried one of the 23 single nucleotide polymorphisms (SNPs). Of these SNPs, 22 and 1 were nonsynonymous and synonymous mutations, respectively. All of the mutations were detected at low prevalence $(0.4-$ $3.4 \%)$. N458Ywas the most common mutation $(8 / 40,20 \%)$ followed by P574L (5/40, 12.5\%) and F446I (4/40, 10\%) mutations. The artemisinin resistance associated mutation (C580Y) was found in only $0.9 \%$ of isolates and the I543T, $\mathrm{R} 539 \mathrm{~T}$ and $\mathrm{Y} 493 \mathrm{H}$ mutations associated with delayed PCT in the Cambodian isolates were not detected in any of the Thailand isolates. The $17.4 \%$ (38/227) of samples collected from Mae Sot were found to carry a SNP on the K13 propeller domain. Although the number of samples collected from Ranong province was very small, the P574L mutation was frequently observed $(2 / 8,25 \%)$. The prevalence of K13 propeller domain polymorphisms is summarised in Table 1.

The Pfmdr1 gene was successfully amplified in 113 out of 235 samples. The number of gene copies of 1, 2, 3 and $\geq 4$ were found in $65(57.5 \%), 14(12.4 \%), 17(15 \%)$ and $17(15 \%)$ samples, respectively. Median $p f m d r 1$ gene copy number in parasites collected from Mae Sot and Ranong were $3(2-4)$ and $3(2-3)$ copies, respectively. Forty (n $=42)$ and $85(n=6) \%$ of the isolates collected from Mae Sot and Ranong, respectively, had multiple copies of the pfmdrl gene.

The information on the pfmdrl gene copy number together with K13 propeller domain mutation was available in 12 out of $40 \mathrm{~K} 13$-mutated samples. Among these, $5(41.7 \%)$ samples carried a single pfmdrl gene copy with N458Y, P553L, P574L or A578S mutations, while $7(58.3 \%)$ isolates carried $\geq 2$ pfmdrl gene copies with N458Y or P574L mutations.

\section{DISCUSSION}

Twenty-two nonsynonymous and one synonymous mutations were detected in 37 isolates of Plasmodium falciparum from the Thai-Myanmar border (Tak and Ranong provinces of Thailand). Among the 23 mutations, seven were previously reported in isolates from Asian countries, i.e. F446I (Feng et al. 2015a, Huang et al. 2015b, Wang et al. 2015a), N458Y (Ariey et al. 2014, Wang et al. 2015b, Putaporntip et al. 2016), A481T (Nyunt et al. 2015, Takala-Harrison et al. 2015, Putaporntip et al. 2016, Ye et al. 2016), P527H (Putaporntip et al. 2016), R529K (Win et al. 2016), P553L (Ariey et al. 2014, Huang et al. 2015b, Takala-Harrison et al. 2015, Ye et al. 2016) and R561H (Ariey et al. 2014, Putaporntip et al. 2016). Seven mutations were previously detected in isolates from African countries, i.e. D464E (Huang et al. 2015a, Madamet et al. 2017), A504T 
Table 1. Prevalence of K13 propeller domain polymorphisms in 235 isolates of Plasmodium falciparum isolates collected from patients with acute uncomplicated malaria residing in areas along the Thai-Myanmar border during 2006-2010.

\begin{tabular}{|c|c|c|c|c|c|c|c|}
\hline \multirow[b]{2}{*}{ Amino acid change } & \multirow[b]{2}{*}{ Nucleotide change (locus) } & \multicolumn{5}{|c|}{ No of samples (year) } & \multirow{2}{*}{$\begin{array}{c}\text { Total } \\
\mathrm{n}[\% \text { in mutated parasites; } \% \text { in total }]\end{array}$} \\
\hline & & ๖ & હ̊ํ․ & $\stackrel{\infty}{\stackrel{\Upsilon}{\circ}}$ & ஓे & $\stackrel{0}{\stackrel{0}{\circ}}$ & \\
\hline I437T & ATT to AcT(1310) & 0 & 1 & 1 & 0 & 0 & $2[5 ; 0.9]$ \\
\hline V445G & GTA to $\operatorname{GgA}(1334)$ & 0 & 1 & 0 & 0 & 0 & $1[2.5 ; 0.4]$ \\
\hline $\mathrm{F} 446 \mathrm{I}^{\mathrm{a}}$ & TTT to aTT(1336) & 0 & 3 & 1 & 0 & 0 & $4[10 ; 1.7]$ \\
\hline F451I & TTT to aTT(1351) & 0 & 1 & 0 & 0 & 0 & $1[2.5 ; 0.4]$ \\
\hline $\mathrm{E} 455 \mathrm{~K}$ & GAA to aAA(1363) & 0 & 1 & 0 & 0 & 0 & $1[2.5 ; 0.4]$ \\
\hline N458Ya & AAT to tAT(1372) & 0 & 0 & 1 & 7 & 0 & $8[20 ; 3.4]$ \\
\hline D464E & GAT to GAa(1392) & 0 & 1 & 0 & 0 & 0 & $1[2.5 ; 0.4]$ \\
\hline A481T & GCT to $\mathrm{aCT}(1441)$ & 0 & 1 & 0 & 0 & 0 & $1[2.5 ; 0.4]$ \\
\hline A504T & GCT to $\mathrm{aCT}(1510)$ & 0 & 1 & 0 & 0 & 0 & $1[2.5 ; 0.4]$ \\
\hline D512N & GAT to aAT(1534) & 0 & 1 & 0 & 0 & 0 & $1[2.5 ; 0.4]$ \\
\hline $\mathrm{R} 513 \mathrm{H}$ & CGT to CaT(1538) & 0 & 1 & 0 & 0 & 0 & $1[2.5 ; 0.4]$ \\
\hline R529K & AGA to $\mathrm{AaA}(1586)$ & 0 & 1 & 0 & 0 & 0 & $1[2.5 ; 0.4]$ \\
\hline T535A & ACG to $\mathrm{gCG}(1603)$ & 0 & 1 & 0 & 0 & 0 & $1[2.5 ; 0.4]$ \\
\hline P553L $\mathrm{L}^{\mathrm{c}}$ & CCG to $\mathrm{CtG}(1658)$ & 0 & 1 & 0 & 0 & 0 & $1[2.5 ; 0.4)$ \\
\hline $\mathrm{R} 561 \mathrm{H}^{\mathrm{a}}$ & CGT to CaT(1682) & 0 & 1 & 1 & 0 & 0 & $2[5 ; 0.9]$ \\
\hline E567D & GAG to GAc(1701) & 0 & 1 & 0 & 0 & 0 & $1[2.5 ; 0.4]$ \\
\hline T573A & $\mathrm{ACC}$ to $\mathrm{gCC}(1717)$ & 0 & 1 & 0 & 0 & 0 & $1[2.5 ; 0.4]$ \\
\hline P574L ${ }^{a}$ & $\mathrm{CCT}$ to $\mathrm{CtT}(1721)$ & 1 & 0 & 2 & 1 & 1 & $5[12.5 ; 2.1]$ \\
\hline $\mathrm{A} 578 \mathrm{~S}^{\mathrm{d}}$ & GCT to tCT(1732) & 0 & 0 & 0 & 1 & 0 & $1[2.5 ; 0.4]$ \\
\hline $\mathrm{C} 580 \mathrm{Y}^{\mathrm{b}}$ & TGT to TaT(1739) & 0 & 1 & 0 & 1 & 0 & $2[5 ; 0.9]$ \\
\hline M608V & ATG to gTG(1822) & 0 & 1 & 0 & 0 & 0 & $1[2.5 ; 0.4]$ \\
\hline L618L & TTA to $\operatorname{TTg}(1857)$ & 0 & 1 & 0 & 0 & 0 & $1[2.5 ; 0.4]$ \\
\hline V637A & GTT to GcT(1910) & 0 & 0 & 1 & 0 & 0 & $1[2.5 ; 0.4]$ \\
\hline Total & & 1 & 21 & 7 & 10 & 1 & $40[100,17.2]$ \\
\hline
\end{tabular}

${ }^{a}$ Mutations commonly found in the area 1 (western Thailand, Myanmar and China) (Menard et al. 2016a)

${ }^{b}$ Mutation commonly found in the area 2 (Cambodia, Vietnam and Laos) (Menard et al. 2016a)

${ }^{\mathrm{c}}$ Mutation found in the area1 and 2 (Menard et al. 2016a)

${ }^{\mathrm{d}}$ Mutation commonly found in African countries (Menard et al. 2016a)

(Huang et al. 2015a), R513H (Taylor et al. 2015), T535A (Kamau et al. 2015), E567D (Kamau et al. 2015), M608V (Ouattara et al. 2015, Taylor et al. 2015) and V637A (Cooper et al. 2015). Three mutations which were previously detected in both Asian and African countries were also detected in this study, i.e. P574L (Ariey et al. 2014, Feng et al. 2015b, Nyunt et al. 2017), A578S (Conrad et al. 2014; Balikagala et al. 2017) and C580Y (Ariey et al. 2014, bosman et al. 2014; Nyunt et al. 2017).

In the present study, low prevalence $(0.4-3.3 \%)$ of variable amino acid variants was detected in the parasite isolates. Five mutations which have been shown to be linked with the presence of parasites on day 3 after ACT treatment (F446I, N458Y, P553L, P574L and C580Y) (Menard et al. 2016a) were detected in 20 out of 40 mutant samples (50\%). C580Y was detected only in two samples, whereas none of the mutations associated with delayed PCT (I543T, R539T and Y493H) were found.

An in vitro artemisinin susceptible phenotypic A578S allele (Menard et al. 2016a), which is commonly found in Africa, was detected in only one sample. It is interesting to note that the predominant status of mutation alleles detected in this study changed from year to year. The F446I mutation, which was reported to be associated with delayed PCT in China (Huang et al. 2015b), was predominant in 2007. The N458Y mutation, which is associated with delayed PCT in Cambodia, was predominantly detected in 2009. It is possible that other factors apart from parasite genetic factors also contribute to the variation of
K13 mutations. These include differences in the ACT (artemisinin-based combination therapy) regimen used in each country, malaria endemic areas, patterns of malaria transmission and mosquito vector and human host factors.

The restriction in individual K13 nonsynonymous mutations in different geographic localities has been reported (Menard et al. 2016a).

The C580Y, R539T, Y493H and I543T mutations were found to be specific in isolates of $P$. falciparum from Cambodia, Vietnam and Laos. The F446I, N458Y, P574L and $\mathrm{R} 561 \mathrm{H}$ mutations were more specific to the isolates from western Thailand, Myanmar and China. The P553L allele was distributed in countries to both the west and east of Thailand (Menard et al. 2016a). The parasite isolates in this study carried the C580Y, F446I, N458Y, P574L, R561H and P553L mutations which were a combination of mutation alleles found in the isolates from countries both the east and west of Thailand. It is not clear whether the observed K13 mutations found in these samples occurred due to local emergence of artemisinin resistance, or were disseminated from other countries, particularly Cambodia. Numerous emergence events alongside spreading of a small group of mutations for artemisinin resistance were identified by flanking haplotype assessment. Some haplotypes were distributed across the areas and some were area-specific (Menard et al. 2016a). Interestingly, three mutation alleles of $\mathrm{K} 13$ gene were detected in the isolates of $P$. falciparum in Thailand about four years before the introduction of ACT for clinical use in the country. 
In addition, the prevalence of these mutations has also increased over time. This observation may suggest natural selection process on K13 mutation in response to ACT (Putaporntip et al. 2016). Pfmdrl amplification is a beneficial molecular marker associated with resistance to mefloquine in field isolates (Price et al. 2004). Increased copy number of $p f m d r l$ gene is also associated with decreased parasite susceptibility to lumefantrine, halofantrine, quinine and artemisinin (Sidhu et al. 2006).

In Thailand, the continuous and extensive use of mefloquine is the major cause of the observed high prevalence of increased $p f m d r 1$ number. The observed high frequency of parasite isolates with multiple copies of $p f m d r l$ found in this present study was consistent with that reported in previous studies (Mungthin et al. 2014, Phompradit et al. 2014, Srimuang et al. 2016). Pfmdr1 amplification is related to decreased sensitivity to mefloquine but increased in vitro parasite sensitivity to piperaquine (Veiga et al. 2012). Previous studies in Cambodia supported this finding.

Parasite isolates with de-amplification of $p f m d r l$ gene regained susceptibility to mefloquine after replacement of artesunate-mefloquine with a dihydroartemisinin-piperaquine combination regimen (Lim et al. 2015). This may suggest difference in mechanism of parasite resistance to artemisinin. Thailand has just replaced a three-day course of artesunate-mefloquine with dihydroartemisinin-piperaquine regimen in 2015. This policy might improve the clinical efficacy of ACT for treatment of uncomplicat- ed $P$. falciparum in the country where a high prevalence of parasites with multiple $p f m d r 1$ gene copies remains. Nevertheless, resistance of $P$. falciparum to dihydroartemisinin-piperaquine has now been reported in Cambodia (Amaratunga et al. 2016, Chaorattanakawee et al. 2016). Spread of resistant parasites from east to west of the country is a serious concern.

In summary, the study provided the genetic background of mutations on K13 propeller domain and pfmdr1 amplification in isolates of $P$. falciparum after a decade of clinical use of artesunate-mefloquine in Thailand. Low prevalence of isolates with K13 mutations but high prevalence of isolates with multiple $p f m d r l$ gene copies were found. It remains uncertain whether changing treatment policy to dihydroartemisinin-piperaquine would effectively and sustainably limit artemisinin resistance. Intensive surveillance and monitoring of new emergence and identification of artemisinin resistant-associated mutations in K13 and other candidate marker genes in conjunction with in vitro and clinical efficacy assessment in a larger number of clinical samples are essential.

Acknowledgements. We thank Mrs. Kalaya Ruengweerayut and the staff of malaria clinics in Mae Sot, Tak and Ranong, Thailand. The study was supported by Center of Excellence in Pharmacology and Molecular Biology of Malaria and Cholangiocarcinoma of Thammasat University and National Research Council of Thailand (NRCT).

\section{REFERENCES}

Adeel A., Baird K., Bosman A., D’Alessandro U., Olliaro P., Schapira A., Watkins W. (Eds.) 2003: Assessment and Monitoring of Antimalarial Drug Efficacy for Treatment of Uncomplicated Falciparum Malaria. Geneva, Switzerland, 60 pp.

Amaratunga C., Lim P., Suon S., Sreng S., Mao S., Sopha C., Sam B., Dek D., Try V., Amato R., Blessborn D., Song L., Tullo G.S., Fay M.P., Anderson J.M., Tarning J., FairHURST R.M. 2016: Dihydroartemisinin-piperaquine resistance in Plasmodium falciparum malaria in Cambodia: a multisite prospective cohort study. Lancet Infect. Dis. 16: 357-365.

Antony H.A., Pariua S.C. 2016: Antimalarial drug resistance: an overview. Trop. Parasitol. 6: 30-41.

Ariey F., Witkowski B., Amaratunga C., Beghain J., Langlois A.C., Khim N., Kim S., Duru V., Bouchier C., Ma L., Lim P., Leang R., Duong S., Sreng S., Suon S., Chuor C.M., Bout D.M., Menard S., Rogers W.O., Genton B., Fandeur T., Miotto O., Ringwald P., Le Bras J., Berry A., Barale J.C., Fairhurst R.M., Benoit-Vical F., MerCereau-Puijalon O., Menard D. 2014: A molecular marker of artemisinin-resistant Plasmodium falciparum malaria. Nature 505: 50-55.

Ashley E.A., Dhorda M., Fairhurst R.M., Amaratunga C., Lim P., Suon S., Sreng S., Anderson J.M., Mao S., Sam B., Sopha C., Chuor C.M., Nguon C., Sovannaroth S., Pukrittayakamee S., Jittamala P., Chotivanich K., Chutasmit K., Suchatsoonthorn C., Runcharoen R., Hien T.T., Thuy-Nhien N.T., Thanh N.V., Phu N.H., Htut Y., Han K.T., Aye K.H., Mokuolu O.A., Olaosebikan R.R., Folaranmi O.O., Mayxay M., Khanthavong M., Hongvanthong B., Newton P.N., Onyamboko M.A., Fanello C.I., Tshefu A.K., Mishra N., Valecha N., Phyo A.P., Nosten F., Yi P., Tripura R., Borrmann S., Bashraheil
M., Peshu J., Faiz M.A., Ghose A., Hossain M.A., Samad R., Rahman M.R., Hasan M.M., Islam A., Miotto O., Amato R., Macinnis B., Stalker J., Kwiatkowski D.P., Bozdech Z., Jeeyapant A., Cheah P.Y., Sakulthaew T., Chalk J., Intharabut B., Silamut K., Lee S.J., Vihokhern B., Kunasol C., Imwong M., Tarning J., Taylor W.J., Yeung S., Woodrow C.J., Flegg J.A., Das D., Smith J., Venkatesan M., Plowe C.V., Stepniewska K., Guerin P.J., DondorP A.M., Day N.P., White N.J. 2014: Spread of artemisinin resistance in Plasmodium falciparum malaria. N. Engl. J. Med. 371: 411-423.

Balikagala B., Mita T., Ikeda M., Sakurai M., Yatsushiro S., Takahashi N., Tachibana S.I., Auma M., Ntege E.H., Ito D., Takashima E., Palacpac N.M., Egwang T.G., Onen J.O., Kataoka M., Kimura E., Horii T., Tsuboi T. 2017: Absence of in vivo selection for K13 mutations after artemether-lumefantrine treatment in Uganda. Malar. J. 16: 23.

Chaorattanakawee S., Lon C., Jongsakul K., Gawee J., Sok S., Sundrakes S., Kong N., Thamnurak C., Chann S., Chattrakarn S., Praditpol C., Buathong N., Uthaimongkol N., Smith P., Sirisopana N., Huy R., Prom S., Fukuda M.M., Bethell D., Walsh D.S., Lanteri C., SAUNDERS D. 2016: Ex vivo piperaquine resistance developed rapidly in Plasmodium falciparum isolates in northern Cambodia compared to Thailand. Malar. J. 15: 519.

Conrad M.D., Bigira V., Kapisi J., Muhindo M., Kamya M.R., Havlir D.V., Dorsey G., Rosenthal P.J. 2014: Polymorphisms in K13 and falcipain-2 associated with artemisinin resistance are not prevalent in Plasmodium falciparum isolated from Ugandan children. PLoS ONE 9: e105690.

Cooper R.A., Conrad M.D., Watson Q.D., Huezo S.J., Ninsimma H., Tumwebaze P., Nsobya S.L., Rosenthal P.J. 2015: 
Lack of artemisinin resistance in Plasmodium falciparum in Uganda based on parasitological and molecular assays. Antimicrob. Agents Chemother. 59: 5061-5064.

Cui L., Mharakurwa S., Ndiaye D., Rathod P.K., RosenTHAL P.J. 2015: Antimalarial drug resistance: literature review and activities and findings of the ICEMR network. Am. J. Trop. Med. Hyg. 93: 57-68.

Dondorp A.M., Nosten F., Yi P., Das D., Phyo A.P., Tarning J., Lwin K.M., Ariey F., Hanpithakpong W., Lee S.J., Ringwald P., Silamut K., Imwong M., Сhotivanich K., Lim P., Herdman T., An S.S., Yeung S., Singhasivanon P., Day N.P., Lindegardh N., Socheat D., White N.J. 2009: Artemisinin resistance in Plasmodium falciparum malaria. N. Engl. J. Med. 361: 455-467.

Feng J., Li J., Yan H., Feng X., Xia Z. 2015a: Evaluation of antimalarial resistance marker polymorphism in returned migrant workers in China. Antimicrob. Agents Chemother. 59: 326-330.

Feng J., Zhou D., Lin Y., XiaO H., Yan H., Xia Z. 2015b: Amplification of $p f m d r l, p f c r t, p v m d r l$ and K13 propeller polymorphisms associated with Plasmodium falciparum and Plasmodium vivax isolates from the China-Myanmar border. Antimicrob. Agents Chemother. 59: 2554-2559.

Ferreira I.D., Rosario V.E., Cravo P.V. 2006: Real-time quantitative PCR with SYBR Green I detection for estimating copy numbers of nine drug resistance candidate genes in Plasmodium falciparum. Malar. J. 5: 1.

Huang B., Deng C., Yang T., Xue L., Wang Q., Huang S., Su X.Z., Liu Y., Zheng S., Guan Y., Xu Q., Zhou J., Yuan J., Bacar A., Abdallah K.S., Attoumane R., Mliva A.M., Zhong Y., Lu F., Song J. 2015a: Polymorphisms of the artemisinin resistant marker (K13) in Plasmodium falciparum parasite populations of Grande Comore Island 10 years after artemisinin combination therapy. Parasit. Vectors 8: 634.

Huang F., Takala-Harrison S., Jacob C.G., Liu H., Sun X., Yang H., Nyunt M.M., Adams M., Zhou S., Xia Z., Ringwald P., Bustos M.D., Tang L., Plowe C.V. 2015b: A single mutation in K13 predominates in southern China and is associated with delayed clearance of Plasmodium falciparum following artemisinin treatment. J. Infect. Dis. 212: 1629-1635.

Kamau E., Campino S., Amenga-Etego L., Drury E., Ishengoma D., Johnson K., Mumba D., Kekre M., Yavo W., Mead D., Bouyou-Aкоtet M., Apinjoh T., Golassa L., Randrianarivelojosia M., Andagalu B., Maiga-Ascofare O., Amambua-Ngwa A., Tindana P., Ghansah A., MacInnis B., Kwiatkowski D., Dimde A.A. 2015: K13-propeller polymorphisms in Plasmodium falciparum parasites from sub-Saharan Africa. J. Infect. Dis. 211: 1352-1355.

Lim P., Dek D., Try V., Sreng S., Suon S., Fairhurst R.M. 2015: Decreasing pfmdr1 copy number suggests that Plasmodium falciparum in western Cambodia is regaining in vitro susceptibility to mefloquine. Antimicrob. Agents Chemother. 59: 2934-2937.

Madamet M., Kounta M.B., Wade K.A., Lo G., Diawara S., Fall M., Bercion R., Nakoulima A., Fall K.B., Benoit N., Gueye M.W., Fall B., Diatta B., Pradines B. 2017: Absence of association between polymorphisms in the K13 gene and the presence of Plasmodium falciparum parasites at day 3 after treatment with artemisinin derivatives in Senegal. Int. J. Antimicrob. Agents 49: 754-756.

Menard D., Khim N., Beghain J., Adegnika A.A., ShafiulAlam M., Amodu O., Rahim-Awab G., Barnadas C., Berry A., Boum Y., Bustos M.D., Cao J., Chen J.H., Collet L., Cui L., Thakur G.D., Dieye A., Dualle D., Dorkenoo M.A., Евоumbou-Moukoko C.E., Espino F.E., Fandeur T., Ferreira-da-Cruz M.F., Fola A.A., Fuehrer H.P., Hassan A.M., Herrera S., Hongvanthong B., Houze S., Ibrahim M.L., Jahirul-Karim M., Jiang L., Kano S., Ali-Khan W., Khanthavong M., Kremsner P.G., Lacerda M., Leang R., Leelawong M., Li M., Lin K., Mazarati J.B., Menard S., Morlais I., Muhindo-Mavoko H., Musset L., Na-Bang-
Chang K., Nambozi M., Niare K., Noedl H., Ouedraogo J.B., Pillai D.R., Pradines B., Quang-Phuc B., Ramharter M., Randrianarivelojosia M., Sattabongkot J., Sheikh-Omar A., Silue K.D., Sirima S.B., Sutherland C., Syafruddin D., Tahar R., Tang L.H., Toure O.A., Tshibangu-wa-Tshibangu P., Vigan-Womas I., Warsame M., Wini L., Zakeri S., Kim S., Eam R., Berne L., Khean C., Chy S., Ken M., Loch K., Canier L., Duru V., Legrand E., Barale J.C., Stokes B., Straimer J., Witkowski B., Fidock D.A., Rogier C., Ringwald P., Ariey F., MerCereau-Puijalon O. 2016a: A worldwide map of Plasmodium falciparum K13-propeller polymorphisms. N. Engl. J. Med. 374: $2453-2464$.

Menard S., Tchoufack J.N., Maffo C.N., Nsango S.E., Iriart X., Abate L., Tsapi M.T., Awono-Ambene P.H., Abega Mekongo F.A., Morlais I., Berry A. 2016b: Insight into k13-propeller gene polymorphism and ex vivo DHA-response profiles from Cameroonian isolates. Malar. J. 15: 572

Mungthin M., Intanakom S., Sumandittakul N., Suida P., Amsakul S., Sitthichot N., Thammapalo S., Leelayoova S. 2014: Distribution of $p f m d r 1$ polymorphisms in Plasmodium falciparum isolated from southern Thailand. Malar. J. 13: 117.

Na-Bangchang K., Muhamad P., Ruaengweerayut R., Chaijaroenkul W., Karbwang J. 2013: Identification of resistance of Plasmodium falciparum to artesunate-mefloquine combination in an area along the Thai-Myanmar border: integration of clinico-parasitological response, systemic drug exposure and in vitro parasite sensitivity. Malar. J. 12: 263.

Na-Bangchang K., Ruengweerayut R., Mahamad P., Ruengweerayut K., Chaijaroenkul W. 2010: Declining in efficacy of a three-day combination regimen of mefloquine-artesunate in a multi-drug resistance area along the Thai-Myanmar border. Malar. J. 9: 273.

Noedl H., Se Y., Schaecher K., Smith B.L., Socheat D., FUKUDA M.M. 2008: Evidence of artemisinin-resistant malaria in western Cambodia. N. Engl. J. Med. 359: 2619-2620.

Nyunt M.H., Hlaing T., Oo H.W., Tin-Oo L.L., Phway H.P., Wang B., Zaw N.N., Han S.S., Tun T., San K.K., Kyaw M.P., HAN E.T. 2015: Molecular assessment of artemisinin resistance markers, polymorphisms in the K13 propeller and a multidrug-resistance gene in the eastern and western border areas of Myanmar. Clin. Infect. Dis. 60: 1208-1215.

Nyunt M.H., Wang B., Aye K.M., Aye K.H., Han J.H., Lee S.K., Han K.T., Htut Y., Han E.T. 2017: Molecular surveillance of artemisinin resistance falciparum malaria among migrant goldmine workers in Myanmar. Malar. J. 16: 97.

Ouattara A., Kone A., Adams M., Fofana B., Maiga A.W., Hampton S., Coulibaly D., Thera M.A., Diallo N., Dara A., Sagara I., Gil J.P., Bjorkman A., Takala-Harrison S., Doumbo O.K., Plowe C.V., Duimde A.A. 2015: Polymorphisms in the K13-propeller gene in artemisinin-susceptible Plasmodium falciparum parasites from Bougoula-Hameau and Bandiagara, Mali. Am. J. Trop. Med. Hyg. 92: 1202-1206.

Phompradit P., Muhamad P., Wisedpanichiol R., ChaijarOENKUl W., NA-Bangchang K. 2014: Four years' monitoring of in vitro sensitivity and candidate molecular markers of resistance of Plasmodium falciparum to artesunate-mefloquine combination in the Thai-Myanmar border. Malar. J. 13: 23.

Price R.N., Uhlemann A.C., Brockman A., McGready R., Ashley E., Phaipun L., Patel R., Laing K., Looareesuwan S., White N.J., Nosten F., Krishna S. 2004: Mefloquine resistance in Plasmodium falciparum and increased $\mathrm{pfm}$ $d r 1$ gene copy number. Lancet 364: 438-447.

Putaporntip C., Kuamsab N., Kosumin R., Tantimattanasub W., Vejakama P., Sueblinvong T., Seethamchai S., Jongwutiwes S., Hughes A.L. 2016: Natural selection of K13 mutants of Plasmodium falciparum in response to artemisinin combination therapies in Thailand. Clin. Microbiol. Infect. 22: 285.e1-285.e8. 
Sidhu A.B., Uhlemann A.C., Valderramos S.G., Valderramos J.C., Krishna S., Fidock D.A. 2006: Decreasing pfmdrl copy number in Plasmodium falciparum malaria heightens susceptibility to mefloquine, lumefantrine, halofantrine, quinine and artemisinin. J. Infect. Dis. 194: 528-535.

Srimuang K., Miotto O., Lim P., Fairhurst R.M., Kwiatkowski D.P., Woodrow C.J., Imwong M., Tracking ReSistance to Artemisinin C. 2016: Analysis of anti-malarial resistance markers in $p f m d r l$ and $p f c r t$ across southeast Asia in the tracking resistance to artemisinin collaboration. Malar. J. 15: 541.

Takala-Harrison S., Jacob C.G., Arze C., Cummings M.P., Silva J.C., Dondorp A.M., Fukuda M.M., Hien T.T., Mayxay M., Noedl H., Nosten F., Kyaw M.P., Nhien N.T., Imwong M., Bethell D., Se Y., Lon C., Tyner S.D., Saunders D.L., Ariey F., Mercereau-Puijalon O., Menard D., Newton P.N., Khanthavong M., Hongvanthong B., Starzengruber P., Fuehrer H.P., Swoboda P., Khan W.A., Phyo A.P., Nyunt M.M., Nyunt M.H., Brown T.S., Adams M., Pepin C.S., Bailey J., Tan J.C., Ferdig M.T., Clark T.G., Miotto O., Macinnis B., Kwiatkowski D.P., White N.J., Ringwald P., Plowe C.V. 2015: Independent emergence of artemisinin resistance mutations among Plasmodium falciparum in Southeast Asia. J. Infect. Dis. 211: 670-679.

Taylor S.M., Parobek C.M., DeConti D.K., Kayentao K., Coulibaly S.O., Greenwood B.M., Tagbor H., Williams J., Bojang K., Nuie F., Desai M., Kariuki S., Gutman J., Mathanga D.P., Martensson A., Ngasala B., Conrad M.D., Rosenthal P.J., Tshefu A.K., Moormann A.M., Vulule J.M., Doumbo O.K., Ter Kuile F.O., Meshnick
S.R., Bailey J.A., Juliano J.J. 2015: Absence of putative artemisinin resistance mutations among Plasmodium falciparum in sub-Saharan Africa: a molecular epidemiologic study. J. Infect. Dis. 211: $680-688$

Veiga M.I., Ferreira P.E., Malmberg M., Jornhagen L., Bjorkman A., Nosten F., Gil J.P. 2012: pfmdrl amplification is related to increased Plasmodium falciparum in vitro sensitivity to the bisquinoline piperaquine. Antimicrob. Agents Chemother. 56: 3615-3619.

Wang Z., Shrestha S., Li X., Miao J., Yuan L., Cabrera M., Grube C., Yang Z., Cui L. 2015a: Prevalence of K13-propeller polymorphisms in Plasmodium falciparum from China-Myanmar border in 2007-2012. Malar. J. 14: 168

Wang Z., Wang Y., Cabrera M., Zhang Y., Gupta B., Wu Y., Kemirembe K., Hu Y., Liang X., Brashear A., Shrestha S., Li X., Miao J., Sun X., Yang Z., Cui L. 2015b: Artemisinin resistance at the China-Myanmar border and association with mutations in the K13 propeller gene. Antimicrob. Agents Chemother. 59: 6952-6959.

Win A.A., Imwong M., Kyaw M.P., Woodrow C.J., Сhotivanich K., Hanboonkunupakarn B., Pukrittayakamee S. 2016: K13 mutations and pfmdrl copy number variation in Plasmodium falciparum malaria in Myanmar. Malar. J. 15: 110.

World Health Organization. Regional Office for the Western PACIFIC 2015: Strategy for Malaria Elimination in the Greater Mekong Subregion: 2015-2030. WHO, Manila, 64 pp.

Ye R., Hu D., Zhang Y., Huang Y., Sun X., Wang J., Chen X., Zhou H., Zhang D., Mungthin M., Pan W. 2016: Distinctive origin of artemisinin-resistant Plasmodium falciparum on the China-Myanmar border. Sci. Rep. 6: 20100.

Cite this article as: Phompradit P., Chaijaroenkul W., Muhamad P., Na-Bangchang K. 2019: K13 propeller domain mutations and Pfmdrl amplification in Plasmodium falciparum isolates collected from Thai-Myanmar border area in 2006-2010. Folia Parasitol. 66: 006 . 